\title{
Uterine inversion - an obstetrician's nightmare: a series of 3 cases of uterine inversion and a review of management options
}

\author{
Rashmi G. Jalvee*, Reena J. Wani \\ Department of Obstetrics and Gynecology, HBT Medical College and Dr. R. N. Cooper Hospital, Mumbai, Maharashtra, \\ India
}

Received: 23 February 2021

Revised: 03 April 2021

Accepted: 14 April 2021

\section{*Correspondence:}

Dr. Rashmi G. Jalvee,

E-mail: rashmijalvee@yahoo.co.in

Copyright: () the author(s), publisher and licensee Medip Academy. This is an open-access article distributed under the terms of the Creative Commons Attribution Non-Commercial License, which permits unrestricted non-commercial use, distribution, and reproduction in any medium, provided the original work is properly cited.

\begin{abstract}
Acute puerperal uterine inversion is an extremely rare but potentially life-threatening complication in which the uterine fundus collapses within the endometrial cavity and beyond. Although the causes of uterine inversion are unclear, several predisposing factors have been described. Maternal mortality is extremely high unless the condition is recognized and corrected. We present here a series of three cases of uterine inversion managed in our hospital over a period of 3 years. Our first case, Mrs XYZ referred to our hospital after vaginal delivery followed by postpartum collapse. The patient was in hypovolemic shock with $2^{\text {nd }}$ degree uterine inversion. Second case, Mrs ABC referred to our hospital after vaginal delivery and mass coming out of the vagina. The patient had postpartum haemorrhage with $2^{\text {nd }}$ degree uterine inversion. Our third case, Mrs DEF, c/o full term vaginal delivery at our hospital with $2^{\text {nd }}$ degree uterine inversion with postpartum haemorrhage. In all three cases, the patients were explored in the OT under general anaesthesia and uterine reposition was done vaginally. Two of the patients required mechanical ventilation post operatively and all the patients required blood and blood product transfusion. The clinical management, treatment options and surgical nuances of management of uterine inversion are discussed.
\end{abstract}

Keywords: Uterine inversion, Post-partum haemorrhage, Obstetric emergency

\section{INTRODUCTION}

Uterine inversion, a potentially fatal childbirth complication, is a condition where the uterine fundus collapses within the endometrial cavity and beyond. The incidence varies considerably and can range from 1 case in 2000 to 1 case in every 50,000 births. ${ }^{1}$ If not immediately identified, the torrential and often underestimated blood loss can lead to hypovolemic shock and maternal death. Some series of study show mortality rates as high as $15 \%$. $^{2}$

\section{CASE SERIES}

We present here a series of three cases of uterine inversion in our institute over a period of five years and a review of risk factors, clinical features, complications and management and of uterine inversion.

\section{Case 1}

Our first patient was Mrs. XYZ, 23 years old primigravida, 39 weeks pregnant, admitted to our hospital in spontaneous labour. After six hours of active labour, the patient delivered a male child, $3 \mathrm{~kg}$ weight. However, 15 minutes after delivery of the placenta, the patient complained of severe pain in abdomen and the resident noticed heavy bleeding per vagina. On examination, the patient was pale with pulse of $120 / \mathrm{min}$, blood pressure of $86 / 50 \mathrm{~mm} \mathrm{Hg}$. On per abdominal examination, there was abdominal tenderness and the uterine fundus was not palpable. On per vaginal examination, a bulging mass was 
felt in the vagina with clots and heavy bleeding. A diagnosis of $2^{\text {nd }}$ degree uterine inversion was made.

\section{Case 2}

Our second patient was Mrs. ABC, 22 years old, P1L1, referred from private nursing home i/v/o postpartum hemorrhage. The patient had spontaneous vaginal delivery. Following removal of the placenta, there was torrential bleeding per vagina. The patient arrived in our hospital, 1 hour and 40 minutes after delivery. On examination, the patient was drowsy, pale with feeble pulse, 156/min, systolic BP was $70 \mathrm{~mm} \mathrm{Hg}$. On per abdominal examination, the uterine fundus was not palpable and there was supra pubic tenderness. On per speculum examination, active bleeding was present. A grossly congested and hyperaemic mass with smooth surface was seen in the vagina suggestive of $2^{\text {nd }}$ degree uterine inversion. There was a right medio lateral unsutured episiotomy.

\section{Case 3}

Our third patient was Mrs. DEF, a 26 years old lady, P1L1, referred from peripheral maternity home $\mathrm{i} / \mathrm{v} / \mathrm{o}$ uterine inversion with postpartum hemorrhage. The patient was a c/o full-term pregnancy with pre-eclampsia who had prolonged second stage of labour. Following removal of placenta, there was massive bleeding per vagina. The patient arrived at our institute, 2 hours 10 minutes after delivery. On examination, the patient was breathless and pale. The pulse was feeble, 144/min, the systolic blood pressure (BP) was $70 \mathrm{~mm} \mathrm{Hg}$. On per abdominal examination, there was dimpling of the uterine fundus. Per vaginal examination revealed a bulging globular mass in the vagina suggestive of $2^{\text {nd }}$ degree uterine inversion.

Table 1 below shows the approximate interval of time between the delivery and the diagnosis/referral of cases.

Table 1: Time interval between delivery and diagnosis/referral.

\begin{tabular}{|ll|}
\hline Case & Interval \\
\hline Case 1 & 20 minute \\
\hline Case 2 & 1 hour 40 minute \\
\hline Case 3 & 2 hours 10 minute \\
\hline
\end{tabular}

Table 2 above shows the laboratory investigations of the three patients.

As can be seen from Tables 1 and 2, as the interval of time between inversion and management increases, there is a parallel increase in the fall in haemoglobin. This signifies the rapidity with which blood loss occurs in cases of uterine inversions.

Time is of the essence in the management of these cases. Once the diagnosis is made, uterine replacement should be attempted promptly. Nasal oxygen was started. Two wide bored intravenous lines were taken and intravenous crystalloids were started. Investigations were sent and blood was sent for grouping and cross matching. Two pints of blood were issued and FFPs were arranged. Patients were catheterized and iv antibiotics were given.

Table 2: Laboratory investigations of patients.

\begin{tabular}{|llll|}
\hline Investigations & Case 1 & Case 2 & Case 3 \\
\hline $\begin{array}{l}\text { HB (pre-delivery) } \\
\text { (gm \%) }\end{array}$ & 10.8 & 11.4 & 10.8 \\
\hline $\begin{array}{l}\text { HB (post-diagnosis) } \\
\text { (gm \%) }\end{array}$ & 7.8 & 5.3 & 5.1 \\
\hline WBC & 13300 & 12300 & 16700 \\
\hline Platelets & 190000 & 156000 & 210000 \\
\hline PT/ INR & $13 / 1.0$ & $14 / 1.1$ & $16 / 1.2$ \\
\hline Creatinine & 1 & 0.9 & 0.9 \\
\hline
\end{tabular}

All three cases were shifted to the operation theatre within half an hour of diagnosis. General anaesthesia was given. Cases 2 and 3 were started on ionotropic support with nor adrenaline. Blood was started intra-operatively in all three cases.

The patients were put in lithotomy position. Manual reposition of uterus by Johnson's method was attempted. ${ }^{3}$

The principle of this method is that the part of the uterus which comes down last should go back first. The uterus was lifted into the abdominal cavity above the level of the umbilicus to facilitate repositioning. The fundus was held in the palm of the hand and the fingers were inserted at the utero-cervical junction. Gentle digital pressure was applied at the utero-cervical ring to facilitate passage of fundus through the ring. Once the uterus was reposited, the fist was retained within the uterus and uterotonics were started. Oxytocin 40 units in $500 \mathrm{ml}$ of normal saline infusion was started and methyl ergometrine was given intra muscularly. Tablet misoprostol 800 micrograms was inserted rectally. Once uterine tone was regained, the fist was slowly removed. The episiotomy was sutured.

All three patients were shifted to the intensive care unit (ICU) for monitoring. Oxytocics were continued over 2448 hours and patients were kept on mechanical ventilation and ionotropic support for the next 18-24 hours. Case 1 received 2 whole blood and 2 FFPs while cases 2 and 3 received 4 pints blood and 4 FFPs.

Post operatively, all three cases recovered uneventfully. Injectable iron was given for correction of anaemia. Patients were discharged between days 5 and 7 .

\section{DISCUSSION}

Puerperal uterine inversion is a rare and unpredictable obstetric emergency in which a woman can have profound shock. The earliest mention of uterine inversion in 
literature is since the time of Hippocrates but it was not until the 16th century, during the time of Ambroise-Paré, that it was understood. ${ }^{4}$

\section{Etiology}

Mismanagement of the third stage of labour is the commonest cause of acute uterine inversion with inexperience of the birth attendant an important contributory factor. Premature traction on the umbilical cord before the placenta is separated or applying fundal pressure are implicated in the inversion of uterus. A review of our case series revealed that two of the deliveries were conducted by junior residents and one patient was delivered by staff nurse. Risk factors for uterine inversion, such as placenta accreta, a short umbilical cord, augmentation of labour, rough procedures (e.g. the Crede maneuver, excessive cord traction and manual removal of the placenta without sign of placenta separation) for placental removal, have been previously reported. ${ }^{5}$

In more than half the cases, no risk factor is identified.

The pathophysiology of acute uterine inversion involves relaxation of part of the uterine wall which causes a part of the wall to prolapse through the dilated cervix along with simultaneous downward traction on the uterine fundus leading to inversion of the uterus.

\section{Degrees of uterine inversion}

Table 3 shows the degrees of uterine inversion. ${ }^{1}$

Table 3: Degrees of uterine inversion.

\begin{tabular}{|ll|}
\hline Degree & Uterine inversion \\
\hline 2nd & $\begin{array}{l}\text { Inverted fundus upto the cervix } \\
\text { into the vagina }\end{array}$ \\
\hline 3rd & $\begin{array}{l}\text { Prolapse of inverted uterus outside the } \\
\text { vagina }\end{array}$ \\
\hline
\end{tabular}

\section{Diagnosis}

The diagnosis of uterine inversion is a clinical diagnosis. The condition is often suspected in the presence of heavy bleeding after childbirth or after failure to palpate the uterine fundus during abdominal examination. This may lead to hypotension, tachycardia and eventually hypovolemic shock. Symptoms of uterine inversion include severe abdominal pain, heavy vaginal bleeding and a lump in the vagina. Signs of uterine inversion are profound hypotension, bradycardia in the presence of neurogenic shock, abdominal tenderness, absence of uterine tenderness on abdominal examination and a lump in the vagina.

Shock is out of proportion to apparent blood loss due to neurogenic shock. There is stretching of infudibulo-pelvic and round ligaments, ovaries and associated nerves as these structures are pulled into the crater of the inversion causing a strong vasovagal stimulus.

\section{Treatment}

Simultaneous resuscitation with uterine reposition forms the cornerstone of management. Resuscitation with oxygen, crystalloids, blood and blood products should begin immediately. Any ongoing oxytocic drugs should be stopped immediately.

\section{Non-surgical methods}

\section{Manual replacement}

If the diagnosis is made soon after delivery, the initial approach is to immediately reduce the uterus with manual pressure through the vagina (Johnson manoeuvre). Immediate reposition minimizes the blood loss and improves the chances of correction, since the longer the time between the inversion and the procedure, lower is the success rate. This is due to involution of the cervix which causes a rigid ring that makes restoration of normal uterus anatomy difficult. ${ }^{6}$

The principle of Johnson's method is that the part of the uterus which comes down last should go back first. Holding the fundus in the palm and keeping the tips of the fingers at the uterocervical junction, the fundus is raised above the level of the umbilicus. Digital pressure must be applied slowly and sequentially. This places the uterine ligaments under tension. The tension generated relaxes and widens the cervical ring and facilitates the passage of the fundus though the ring and correcting the inversion.

\section{O Sullivan's hydrostatic method}

This is a method of reducing the uterine inversion by instilling warm normal saline in vagina. Gupta et al reported successful reposition of uterus in 6 cases of uterine inversion with normal saline instillation. ${ }^{7}$

Ogeuh and Ayida described a modification of this method where instead of the assistant's hands, a silicon cup is used. ${ }^{8}$ Different methods for preventing reinversion have recently been reported; and use of an intra-uterine Bakri balloon is an effective preventive measure against reinversion..$^{9,10}$

Infection, failure of the procedure and saline embolus are some of the possible complications of this method. The World Health Organisation recommends that if manual replacement fails, hydrostatic methods should be used. ${ }^{11}$

\section{Surgical management}

Surgical methods are rarely required. Both abdominal and vaginal methods are described. 


\section{Abdominal}

In Huntington's operation, clamps are placed on the round ligament, near its insertion in the uterus, and traction is applied while the assistant exerts upward pressure on the fundus through the vagina. This is the simplest technique and has a lower risk of complications. ${ }^{12}$

In Haultain's operation, the cervical ring is incised posteriorly with a longitudinal incision. The rest of the steps are same as the Huntington's method. Once the uterus has been repositioned, incisions on the cervix, uterus and vagina are closed with interrupted sutures. Uterotonics are given to maintain contraction of the uterus.

Another surgical technique by vaginal route was described by Spinelli. ${ }^{13}$ In this technique, the surgeon dissects of the vesico-uterine space and makes an incision on the cervix, allowing the uterus to return to its original position. In Kustner's method, the incision on the cervix is made posteriorly.

There are published case reports of laparoscopic-assisted reduction of uterine inversion, but these are performed rarely. $^{14}$

\section{Role of tocolysis in reposition of the uterus}

In the presence of a constriction ring, reduction of uterine inversion can be challenging. Tocolysis allows relaxation of the uterus before manual replacement or use of the hydrostatic method. The adverse effect of tocolyticmediated reduction in uterine tone, however, can cause an aggravation of postpartum haemorrhage, which is especially undesirable in the presence of shock. Terbutaline, magnesium sulphate, nitroglycerine have all been described in literature for tocolytic used.

Regardless of the technique, there is no consensus on the timing of the removal of the placenta. However, many authors argue that this removal should occur only after the normal repositioning of the uterus, to reduce blood loss. ${ }^{15}$ After reversal of the clinical condition, it is essential to administrate uterotonic agents (oxytocin or misoprostol) to prevent recurrence.

\section{CONCLUSION}

Uterine inversion is an obstetric complication which requires prompt diagnosis and urgent clinical action. A high index of suspicion is required to diagnose this condition due to rarity of this complication. Premature attempts to remove a partially separated placenta or application of fundal pressure should be avoided. Regardless of treatment, early diagnosis and prompt management will ensure better prognosis. As it is a rare condition, there is limited experience in managing these cases. Therefore, management of uterine inversion should be a part of the residency teaching program.

\section{ACKNOWLEDGMENTS}

Authors would like to thank Dean Sir Dr. Pinakin Gujjar and Dr. Sneha Shirodkar, HOD, OBGY for their guidance and also Stella Cho, undergraduate research associate for her contribution in literature review.

Funding: No funding sources

Conflict of interest: None declared

Ethical approval: Not required

\section{REFERENCES}

1. Dwivedi S, Gupta N, Mishra A, Pande S. Uterine inversion: a shocking aftermath of mismanaged 3rd stage of labour. Int $\mathbf{J}$ Reprod Contracept Obstet Gynecol. 2013;2(3):292-5.

2. Hostetler DR, Bosworth MF. Uterine inversion: A life-threatening obstetric emergency. J Am Board Fam Pract. 2000;13(2):120-3.

3. Johnson AB. A new concept in replacement of the inverted uterus and report of nine cases Am J Obstet Gynecol. 1949;57:557-62.

4. Huntington JL, Boston M.D. Acute inversion of uterus. Med Surg J. 1921;184:376-80.

5. Mirza FG, Gaddipati S. Review Obstetric emergencies. Semin Perinatol. 2009;33(2):97-103.

6. Brokenshire J, Thomas J. Uterine Inversion and Postpartum Hemorrhage. EM Cases. 2016.

7. Gupta P, Sahu RL, Huria A. Acute uterine inversion: a simple modification of hydrostatic method of treatment. Ann Med Health Sci Res. 2014;4(2):264-7.

8. Ogueh O, Ayida G. Acute uterine inversion: A new technique of hydrostatic replacement. $\mathrm{Br} \mathrm{J}$ Obstet Gynaecol.1997;104:951-2.

9. Matsubara S. Combination of an intrauterine balloon and the "holding the cervix" technique for hemostasis of postpartum hemorrhage and for prophylaxis of acute recurrent uterine inversion. Acta Obstetricia et Gynecologica Scandinavica. 2014;93(3):314-5.

10. Ida A, Ito K, Kubota Y, Nosaka M, Kato H, Tsuji Y. Successful reduction of acute puerperal uterine inversion with the use of a bakri postpartum balloon. Case Rep Obstet Gynecol. 2015;424891.

11. World Health Organization. Correcting uterine inversion. Available at: www.who.int/reproductivehealth/ impact/procedures/ correcting p91-94.html. Accessed on 24 January 2021.

12. Huntington JL, Irving FC, Kellogg FS, Mass B. Abdominal reposition in acute inversion of the puerperal uterus. Am J Obstet and Gynaecol. 1928; $15: 34-8$.

13. Neves J, Cardoso E, Araújo C, Santo S, Gonçalves P, Melo A, Rodrigues R, Coelho. Uterine Inversion. AP Acta Med Port. 2006;19(2):181-4.

14. Vijayaraghavan R, Sujatha Y. Acute postpartum uterine inversion with haemorrhagic shock: laparoscopic reduction: a new method of management? BJOG. 2006;113(9):1100-2. 
15. You WB, Zahn CM. Postpartum hemorrhage: abnormally adherent placenta, uterine inversion, and puerperal hematomas. Clin Obstet Gynecol. 2006;49(1):184-97.
Cite this article as: Jalvee RG, Wani RJ. Uterine inversion - an obstetrician's nightmare: a series of 3 cases of uterine inversion and a review of management options. Int J Reprod Contracept Obstet Gynecol 2021;10:2050-4. 